\title{
A STATE FEEDBACK DFIG POWER CONTROL FOR WIND GENERATION
}

\author{
Alfeu J. Sguarezi Filho, André L. F. Murari, Carlos E. Capovilla, José A. T. Altuna, Rogério V. Jacomini* \\ Universidade Federal do ABC - UFABC/CECS, Santo André - SP, Brazil \\ Instituto Federal de Educação, Ciência e Tecnologia de São Paulo - IFSP, Hortolândia - SP, Brazil* \\ e-mail: alfeu.sguarezi, carlos.capovilla,jose.torrico@ufabc.edu.br, andre_murari@hotmail.com,rogeriojacomini@gmail.com.br
}

\begin{abstract}
This paper proposes a state feedback controller for doubly-fed induction generators at variable speed wind. The controller uses pole placement technique, stator flux orientation, and state feedback rotor current vector loops. None conventional PI controller is used on the control. Its algorithm calculates the voltage vector to be supplied to the rotor to certificate that the active and reactive power follow their desired reference values. Experimental results obtained in a hardware setup are carried out to validate the controller operation.
\end{abstract}

Keywords - Doubly-Fed Induction Generators, Pole Placement Control, Power Control, State Feedback Control, Wind Energy.

\section{INTRODUCTION}

The renewable energy systems and especially wind energy have attracted interest due to the increasing concern about $\mathrm{CO}_{2}$ emissions. The wind energy systems using a doublyfed induction generator (DFIG) have some advantages due to variable speed operation and four quadrants active and reactive power capabilities, when compared with fixed speed induction squirrel cage and synchronous generators [1], [2]. The DFIG stator is connected directly to the grid and the rotor is connected to the grid through a bi-directional converter. The rotor converter objective is to control the DFIG active and reactive power flow between the stator and AC supply.

The control of DFIG wind turbine systems is traditionally based on either stator-flux-oriented [3] or stator-voltageoriented [4] vector control. The scheme decouples the rotor current into active and reactive power components. Its active and reactive power control are achieved with rotor current controller [5]. Some investigations using PI controllers and stator-flux-oriented have been presented in [6].

The PI controller problems are the gains tuning and the cross-coupling on DFIG terms in the whole operating range. An interesting method that tries to solve these problems has been presented in [7] and another solution is to use hysteresis controllers, as proposed in [8]. The stator of DFIG is directly connected to the grid, and it, in case of three-phase faults or unbalanced voltages, can destroy the converter or damage the machine. Initially, for converter protection, the crowbar system was used [9]. In this case, when voltage sag is detected, the converter is turned-off, and the rotor is connected to a resistance bank.

Nowadays, there are several control strategies to maintain DFIG connected to the grid during voltage sags, as presented

Manuscript received 24/07/2014; revised 07/01/2015; accepted for publication $02 / 04 / 2015$, by recommendation of the Regular Section Editor Cassiano Rech. in [10], [11]. These strategies have satisfactory dynamic performance, and they do not damage a converter during the voltage sag.

In addition, there are power control schemes for DFIG in normal operation using, for instance, rotor current loops and predictive functional controller [12] or internal mode controller [13], [14]. These controllers have satisfactory power response when compared with the PI ones, but it is hardly to implement them due to the predictive functional controller and internal mode controller formulation. Other possibilities to DFIG power control are fuzzy logic [15], [16], deadbeat [17], model based predictive control [18] or sliding mode control [19], [20]. In the same way, these strategies also have satisfactory ones, although it involves relatively complex transformation of voltages, currents, and control outputs among the stationary, rotor, and synchronous reference frames.

In this context, this paper proposes a state feedback controller for DFIG at variable speed wind generation. Its power control algorithm calculates the voltage vector to be supplied to the rotor to certificate that the active and reactive powers reach their desired reference values. For this action, only proportional gains or integral gains are used in determined points of the closed loop and the ones are designed using the DFIG rotor equations. In this way, this strategy has the advantage of easy implementation.

This paper is organized as follows: besides the introductory section, vector control of DFIG is shown in Section II. The proposed control scheme is presented in Section III. Main experimental results are considered in Section IV to validate the proposed control scheme. Finally, Section V concludes the work.

\section{MACHINE MODEL AND ROTOR CURRENT VECTOR CONTROL}

The DFIG model in synchronous reference frame is given by [21]:

$$
\begin{gathered}
\vec{v}_{1 d q}=R_{1} \vec{i}_{1 d q}+\frac{d \vec{\lambda}_{1 d q}}{d t}+j \omega_{1} \vec{\lambda}_{1 d q} \\
\vec{v}_{2 d q}=R_{2} \vec{i}_{2 d q}+\frac{d \vec{\lambda}_{2 d q}}{d t}+j\left(\omega_{1}-P P \omega_{m e c}\right) \vec{\lambda}_{2 d q}
\end{gathered}
$$

where the relationship between fluxes and currents are:

$$
\begin{aligned}
& \vec{\lambda}_{1 d q}=L_{1} \vec{i}_{1 d q}+L_{M} \vec{i}_{2 d q} \\
& \vec{\lambda}_{2 d q}=L_{M} \vec{i}_{1 d q}+L_{2} \vec{i}_{2 d q} .
\end{aligned}
$$


The machine dynamics is given by:

$$
J \frac{d \omega_{m e c}}{d t}=\frac{3}{2} P P \mathcal{I} m\left(\vec{i}_{1 d q} \vec{\lambda}_{1 d q}^{*}\right)-T_{M}
$$

and the generator active and reactive powers are represented by:

$$
\begin{aligned}
P & =\frac{3}{2}\left(v_{1 d} i_{1 d}+v_{1 q} i_{1 q}\right) \\
Q & =\frac{3}{2}\left(v_{1 q} i_{1 d}-v_{1 d} i_{1 q}\right) .
\end{aligned}
$$

The subscripts 1 and 2 represent the stator and rotor parameters, respectively. $\omega_{1}$ is the synchronous speed, $\omega_{m e c}$ is the machine speed, $R_{1}$ and $R_{2}$ are the per phase electrical resistance of the stator and rotor windings, $L_{1}, L_{2}$, and $L_{M}$ are the proper and mutual inductances of the stator and rotor windings, $\vec{v}$ is the voltage vector, $\vec{i}$ is the current vector, $\vec{\lambda}$ is the flux vector, $P P$ is the machine pair of poles number, $J$ is the load and rotor inertia moment, and $T_{M}$ is the mechanical torque.

The DFIG power control aims independent stator active $P$ and reactive $Q$ power control by means of rotor current regulation. For this purpose, $P$ and $Q$ are represented as functions of each rotor current. Using stator flux oriented control, that decouples $d q$ axis (3), they become:

$$
\begin{gathered}
i_{1 d}=\frac{\lambda_{1}}{L_{1}}-\frac{L_{M}}{L_{1}} i_{2 d} \\
i_{1 q}=-\frac{L_{M}}{L_{1}} i_{2 q}
\end{gathered}
$$

where $\lambda_{1 d}=\lambda_{1}=\left|\vec{\lambda}_{1 d q}\right|$. The active (6) and reactive (7) powers can be reformulated by using (8), (9) and $v_{1 d}=0$ as:

$$
\begin{gathered}
P=-\frac{3}{2} v_{1} \frac{L_{M}}{L_{1}} i_{2 q} \\
Q=\frac{3}{2} v_{1}\left(\frac{\lambda_{1}}{L_{1}}-\frac{L_{M}}{L_{1}} i_{2 d}\right)
\end{gathered}
$$

where $v_{1}=v_{1 q}=\left|\vec{v}_{1 d q}\right|$. Thus, the rotor currents will reflect in stator currents and on stator active and reactive power. Consequently, this principle can be used on stator active and reactive DFIG power control.

\section{A. Rotor Side Equations}

The rotor currents control by using (10) and (11) allows the DFIG power control. The rotor voltage (2), at the synchronous reference frame, using the stator flux position, and (8) and (9) become:

$$
\vec{v}_{2 d q}=\left(R_{2}+j \sigma L_{2} \omega_{s l}\right) \vec{i}_{2 d q}+\sigma L_{2} \frac{d \vec{i}_{2 d q}}{d t}+j \frac{L_{m}}{L_{1}} \omega_{s l} \lambda_{1}
$$

where $\omega_{s l}=\omega_{1}-P P \omega_{m e c}$ and $\sigma=1-\frac{L_{M}^{2}}{L_{1} L_{2}}$.

In space state form, (12) becomes:

$$
\dot{\bar{x}}=A \dot{\bar{x}}+B \bar{u}+G \bar{\omega}
$$

$$
\begin{array}{r}
{\left[\begin{array}{c}
\frac{d i_{2 d}}{d t} \\
\frac{d i_{2 q}}{d t}
\end{array}\right]=\left[\begin{array}{cc}
\frac{-R_{2}}{\sigma L_{2}} & \omega_{s l} \\
-\omega_{s l} & \frac{-R_{2}}{\sigma L_{2}}
\end{array}\right]\left[\begin{array}{c}
i_{2 d} \\
i_{2 q}
\end{array}\right]+\left[\begin{array}{cc}
\frac{1}{\sigma L_{2}} & 0 \\
0 & \frac{1}{\sigma L_{2}}
\end{array}\right]\left[\begin{array}{l}
v_{2 d} \\
v_{2 q}
\end{array}\right]+} \\
{\left[\begin{array}{cc}
0 & \frac{\omega_{s l} L_{M}}{\sigma L_{1} L_{2}} \\
\frac{-\omega_{s l} L_{M}}{\sigma L_{1} L_{2}} & 0
\end{array}\right]\left[\begin{array}{c}
\lambda_{1} \\
0
\end{array}\right] .}
\end{array}
$$

It can occur due to the fact that the mechanical time constant is greater than the electrical ones. Thus, $\omega_{m e c}=$ constant is a valid approximation for each sampling period [22], [23]. In this way, the slip speed $\omega_{s l}$ is constant, since the synchronous speed $\omega_{1}=2 \pi f(f=60 \mathrm{~Hz})$ is determined by the grid.

\section{STATE FEEDBACK POWER CONTROL}

The state feedback power control is a technique that allows null steady state error. The controller is designed by using the overshoot, system frequency, settling time, damping ratio, and space state equation of a linear continuous system [24], [25].

This system can be represented by:

$$
\begin{array}{r}
\dot{\bar{x}}=A \bar{x}+B \bar{u}+G \bar{w} \\
\bar{y}=C \bar{x}
\end{array}
$$

where $\bar{w}$ denotes the perturbation vector and $A, C, B$ and $G 2 \times 2$ matrices for this case. In this paper $C=I$, where $I$ is the identity matrix. The state feedback block diagram is presented in Figure 1.

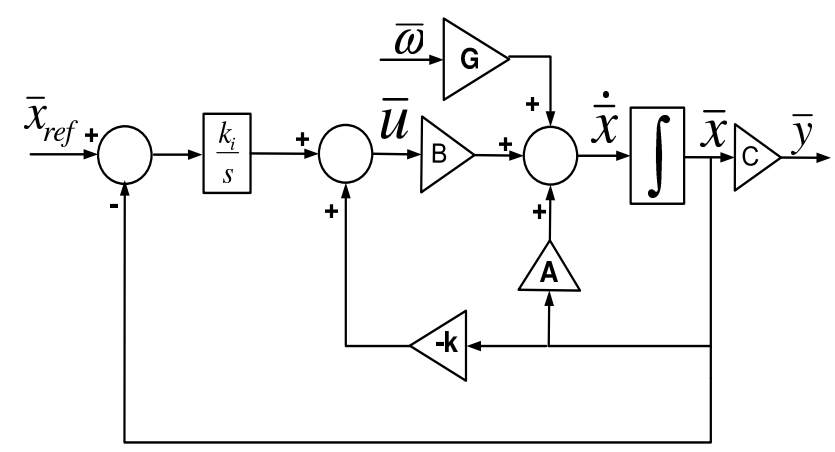

Fig. 1. State feedback control block diagram.

The controller represented by the gain $k$ and $k_{i}$ can be designed using pole placement. The desired poles are obtained for second order system in accordance with the expressions:

$$
\begin{gathered}
p o l_{1,2}=-\omega_{n} \xi \pm j \omega_{n} \sqrt{1-\xi^{2}} \\
\xi=\frac{-\ln (M P)}{\sqrt{\pi^{2}+\ln (M P)^{2}}} \\
\omega_{n}=\frac{4}{\xi t s}
\end{gathered}
$$

where $M P$ is the overshoot, $\omega_{n}$ is the natural frequency, $t s$ is the settling time, and $\xi$ is the damping ratio. The desired characteristic equation is given by [24]:

$$
H=|s I-A+B k| .
$$


The $k$ gains of the state feedback controller are calculated by using the poles calculated from (16)-(18) and the desired characteristic equation (19). The resulting equation is:

$$
|s I-A+B k|=\left(s+p o l_{1}\right)\left(s+p_{0} l_{2}\right)
$$

and $k=\left[\begin{array}{ll}k_{1} & k_{2}\end{array}\right]^{T}$, where $k_{1}$ and $k_{2}$ are the proportional gains.

For null steady state error, a new loop is added using an integrator. The equation of the new loop is:

$$
\dot{\bar{q}}=\text { error }=\bar{x}_{r e f}-\bar{x} .
$$

In this way, the input is given by:

$$
\bar{u}=-k \bar{x}+k_{i} \bar{q}
$$

and $k_{i}=\left[\begin{array}{ll}k_{i 1} & k_{i 2}\end{array}\right]^{T}$, where $k_{i 1}$ and $k_{i 2}$ are integral gains.

The new steady state equation using (15) and (21) is given by:

$$
\begin{gathered}
\dot{\bar{x}}_{1}=A_{1} \bar{x}_{1}+G_{1} \bar{w}+R \bar{x}_{r e f}+B_{1} \bar{u} \\
{\left[\begin{array}{c}
\dot{\bar{x}} \\
\dot{\bar{q}}
\end{array}\right]=\left[\begin{array}{cc}
A & z \\
-I I & z
\end{array}\right]\left[\begin{array}{c}
\bar{x} \\
\bar{q}
\end{array}\right]+\left[\begin{array}{c}
G \\
z
\end{array}\right] \bar{\omega}+\left[\begin{array}{c}
z \\
I
\end{array}\right] \bar{x}_{r e f}+\left[\begin{array}{c}
B \\
z
\end{array}\right] \bar{u}} \\
I I=\left[\begin{array}{ll}
1 & 0 \\
0 & 1
\end{array}\right]
\end{gathered}
$$

where $z$ is a zero matrix.

By using (21)-(25) and the diagram shown in Figure 1, the $k_{i}$ gains are calculated using the modified desired characteristic equation as:

$$
\begin{gathered}
\left|s I-A_{1}+B_{1} k x+G_{1} \bar{\omega}+R\right|= \\
\left(s+\operatorname{pol}_{1}\right)\left(s+\operatorname{pol}_{2}\right)(s+\alpha)(s+\beta)
\end{gathered}
$$

where $\alpha=\beta=2 \times\left|p o l_{1}\right|$, and $k x=\left[\begin{array}{llll}k_{1} & k_{2} & k_{i 1} & k_{i 2}\end{array}\right]^{T}$.

\section{A. Power Control}

The DFIG power control aims the independent control of the active and reactive power using stator flux orientation. The state feedback controller gains are designed by using the model presented in (14) and (16)-(26). In this control application, the rotor current is the state variable and the input is the rotor voltage. Only the rotor voltage equation is used due to the fact the DFIG is directly connected to the grid. An alternative application can be seen in [26]. The converter connected to the grid controls the DC link voltage. This control can be achieved by using voltage orientation and PI controllers as presented in [27]. The state feedback power control block diagram is shown in Figure 2.

A detailed block diagram of the proposed controller, based on (27) and (28), is shown in Figure 3.

To compensate the e.m.f. $\left(\lambda_{1} \omega_{s l} \frac{L_{m}}{\sigma L_{1} L_{2}}\right)$ a feed forward is added to the quadrature rotor component loop. Hence, the components of rotor voltage vector are calculated by:

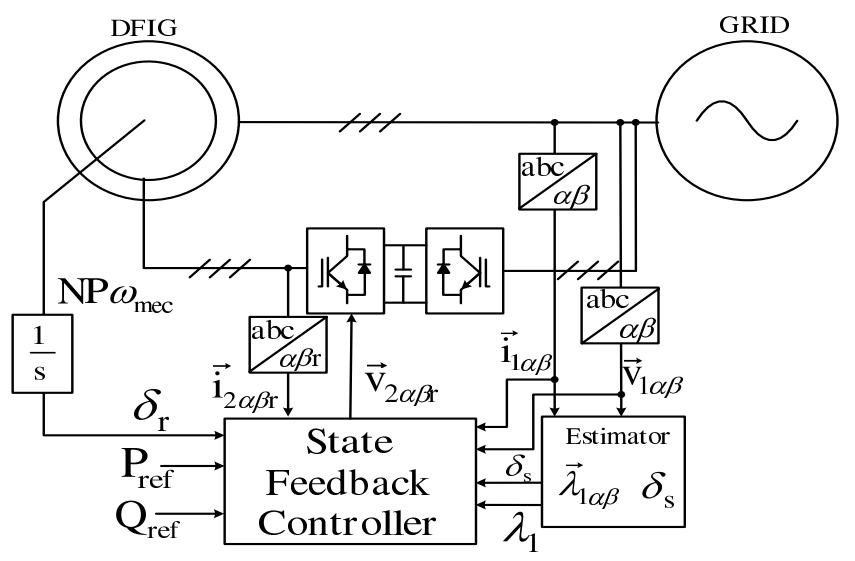

Fig. 2. State feedback power control for DFIG block diagram.

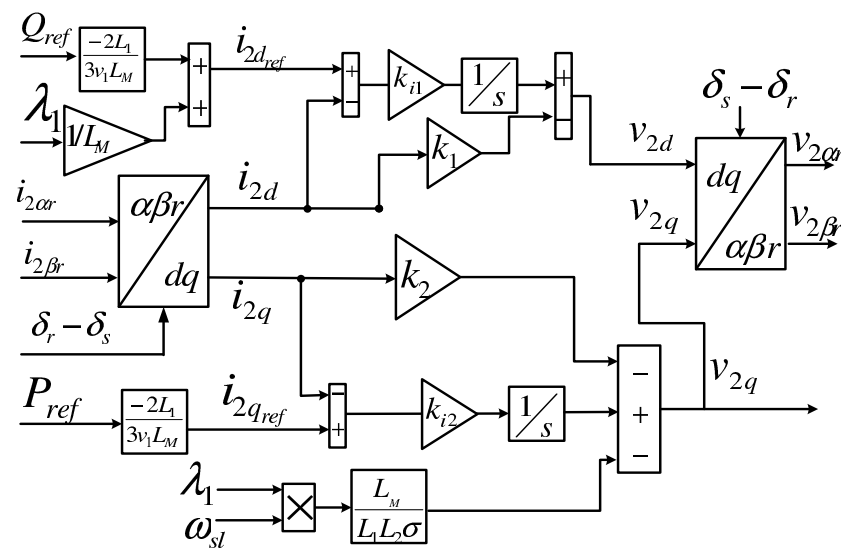

Fig. 3. State feedback power controller in detail.

$$
\begin{gathered}
v_{2 d}=\left(i_{2 d_{r e f}}-i_{2 d}\right) \frac{k_{i 1}}{s}-k_{1} i_{2 d} \\
v_{2 q}=\left(i_{2 q_{r e f}}-i_{2 q}\right) \frac{k_{i 2}}{s}-k_{2} i_{2 q}-\left(\lambda_{1} \omega_{s l} \frac{L_{m}}{\sigma L_{1} L_{2}}\right) .
\end{gathered}
$$

The gains of (27) and (28) are designed using (16)-(26) and the parameters shown in Appendix.

For the active power control, the rotor current reference, using (10), is given by:

$$
i_{2 q_{r e f}}=-\frac{2 P_{r e f} L_{1}}{3 v_{1} L_{M}}
$$

and for the reactive power control by using (11), the rotor current reference is:

$$
i_{2 d_{r e f}}=-\frac{2 Q_{r e f} L_{1}}{3 v_{1} L_{M}}+\frac{\lambda_{1}}{L_{M}} .
$$

Thus, if the gains $k_{1}, k_{2}, k_{i 1}$, and $k_{i 2}$ are correctly calculated, the $d$ (27) and $q$ (28) axis voltage components are calculated by the controller and they are applied to the generator. Then, the active and reactive power convergence to their respective commanded values will occur. The desired rotor voltage in the rotor $\alpha \beta r$ reference frame generates switching signals for the rotor side. Using space vector modulation, it is given by: 


$$
\vec{v}_{2 \alpha \beta r}=\vec{v}_{2 d q} e^{\delta_{s}-\delta_{r}}
$$

\section{B. Estimation}

The power control requires the stator flux magnitude and position, slip speed, synchronous frequency, and the power errors to calculate the active and reactive power values.

The flux estimation, using (1), is given by:

$$
\vec{\lambda}_{1 \alpha \beta}=\int\left(\vec{v}_{1 \alpha \beta}-R_{1} \vec{i}_{1 \alpha \beta}\right) d t .
$$

The integrator was implemented in accordance with [23]. Figure 4 shows the block diagram of the stator flux estimation.

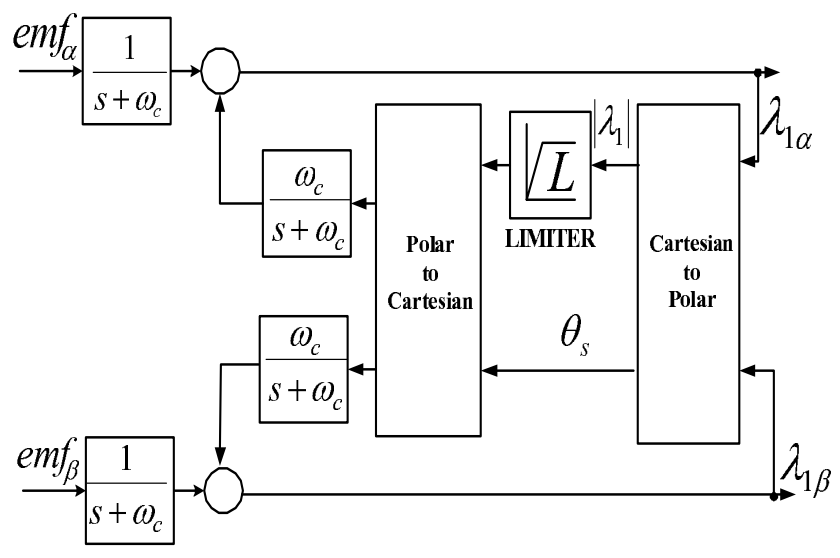

Fig. 4. Block diagram for stator flux estimation.

The flux position, by using (32), is:

$$
\delta_{s}=\arctan \left(\frac{\lambda_{1 \beta}}{\lambda_{1 \alpha}}\right)
$$

and synchronous speed $\omega_{1}$ estimation is given by [28]:

$$
\omega_{1}=\frac{d \delta_{s}}{d t}=\frac{d}{d t} \arctan \left(\frac{\lambda_{1 \beta}}{\lambda_{1 \alpha}}\right) .
$$

So, (34) becomes:

$$
\omega_{1}=\frac{\frac{d \lambda_{2 \beta}}{d t} \lambda_{1 \alpha}-\frac{d \lambda_{1 \alpha}}{d t} \lambda_{1 \beta}}{\left(\lambda_{1 \alpha}\right)^{2}+\left(\lambda_{1 \beta}\right)^{2}} .
$$

Solving (35) and using (32), $\omega_{1}$ is given by:

$$
\omega_{1}=\frac{\left(v_{1 \beta}-R_{1} i_{1 \beta}\right) \lambda_{1 \alpha}-\left(v_{1 \alpha}-R_{1} i_{1 \alpha}\right) \lambda_{1 \beta}}{\left(\lambda_{1 \alpha}\right)^{2}+\left(\lambda_{1 \beta}\right)^{2}} .
$$

This is valid for normal operation. For unbalanced voltage, the methods presented in [29] can be used.

The slip speed estimation, by using the rotor speed and synchronous one, is represented as:

$$
\omega_{s l}=\omega_{1}-P P \omega_{m e c} .
$$

Finally, the rotor reference frame angle is given by:

$$
\delta_{s}-\delta_{r}=\int \omega_{s l} d t
$$

The generator parameters have variations due to its operation. This type of analysis is traditionally based on their resistances. For DFIG, the analysis of stator resistance, used in stator flux estimation, and the rotor resistance, used in rotor voltage calculation, have a negligible impact on system performance for high power generators [4]. Although, the integral component of the proposed controller can minimize the output errors due to the generator parameter variations. So, it allows a null steady state error.

\section{SIMULATION AND EXPERIMENTAL RESULTS}

First, the performance of the proposed state feedback strategy is verified by simulation using MATLAB/Simulink on a $2.2 \mathrm{~kW}$ DFIG, whose nominal values are given in Appendix. The control loop parameters, designed through simulations, are also shown in Appendix.

The experimental setup, used to verify the proposed strategy, consists of DFIG mechanically coupled to a DC motor. The power control is implemented with a power electronic converter using insulated-gate bipolar transistor (IGBT) and controlled by the DSP TMS320F2812 board. The rotor speed is measured by an encoder with 3,800 pulses per revolution, and the rotor voltage commands are modulated by using symmetrical space vector PWM with switching frequency equal to $5 \mathrm{kHz}$. The DC bus voltage of the inverter is $120 \mathrm{~V}$. The DC motor drives DFIG to simulate several wind speed operation. The experimental setup is shown in Figure 5.

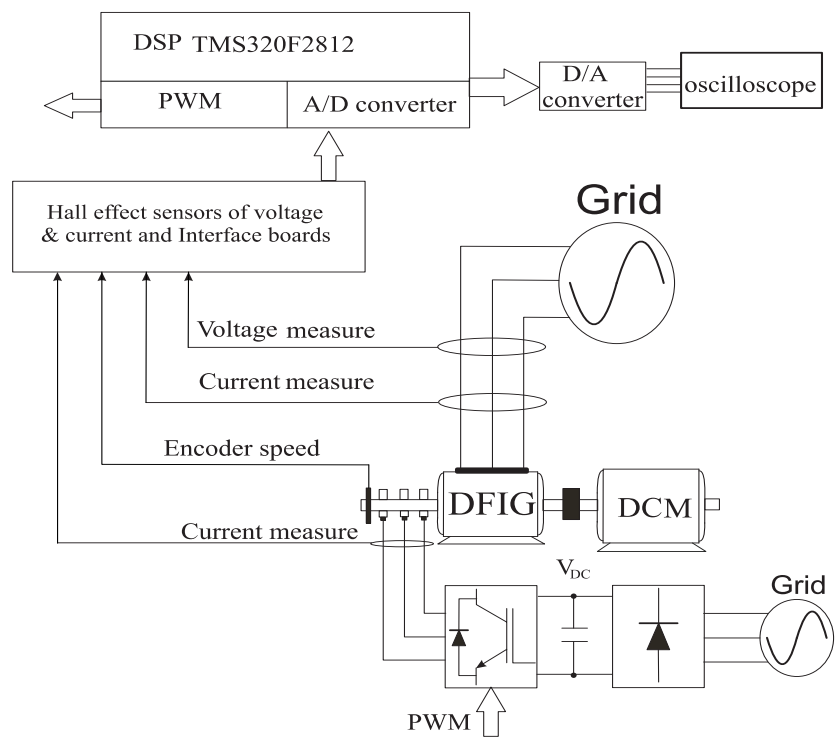

Fig. 5. Experimental setup block diagram.

\section{A. Simulation Results}

During the test at constant speed, the reference stator powers are varied in steps, as shown in Figure 6. In this test, the satisfactory performance of the controller can be seen due to the fact that the rotor current in the synchronous reference frame and stator active and reactive power reach their desired references values with quick dynamic response. The currents in the rotor reference frame are also seen in this figure.

For the test at variable speed, shown in Figure 7, the 

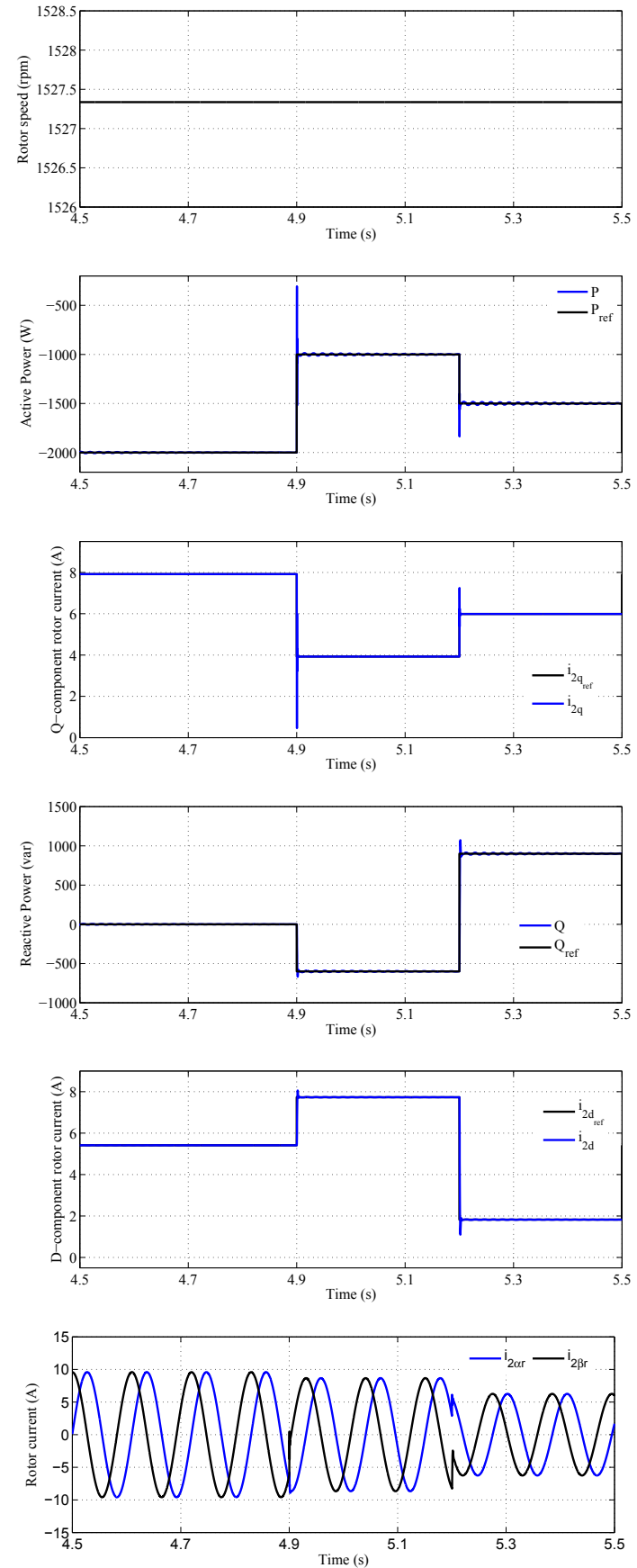

Fig. 6. Test with constant speed.

references of active and reactive powers of the stator are kept constant, at $-2 \mathrm{~kW}$ and 0 var, respectively. It can be seen that even at variable speed, both the rotor current in synchronous reference frame and the stator active and reactive powers have satisfactory performance without steady state error. The rotor currents in $\alpha \beta_{r}$ during this test are also shown in Figure 6.

\section{B. Experimental Results}

In the first test, the generator is operating in the subsynchronous mode at constant speed of 1,527 rpm (85\% of the machine's synchronous speed) and it is analyzed with different active and reactive power steps as set points to test
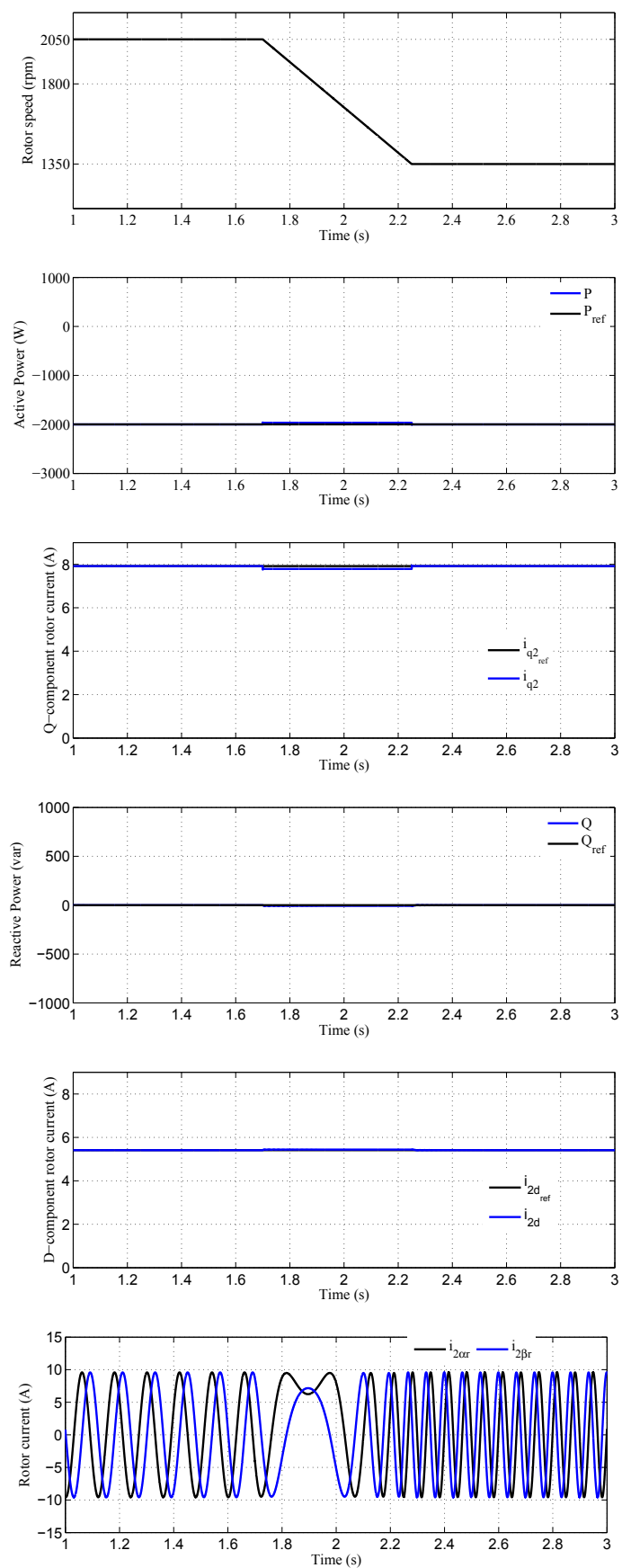

Fig. 7. Test with variable speed.

the dynamic response of the control strategy. The initial active power and the power factor references were, respectively, $-2 \mathrm{~kW}$ and +1 . The active power and the power factor references were changed from $-2 \mathrm{~kW}$ to $-1 \mathrm{~kW}$ and from +1 to -0.85 (capacitive) at $400 \mathrm{~ms}$, respectively. Finally, at $700 \mathrm{~ms}$, the active power reference was changed from $-1 \mathrm{~kW}$ to $-1.5 \mathrm{~kW}$ and, the power factor, from -0.85 to +0.85 (inductive). It can be observed that during the changes of the power references, which are the controlled variables, the proposed control strategy generates the required control voltage $\left(v_{2 d_{\text {ref }}}\right.$ and $\left.v_{2 q_{\text {ref }}}\right)$ from the errors. The ones are between the references and actual values of the $d-q$ rotor 
current components, resulting in transient responses within a few milliseconds of both mode decoupled powers without overshoot and null steady state error.

The active and reactive power responses are shown in Figures 8(a) and 8(b). In details, Figures 9 and 10 for active power and Figures 11 and 12 for reactive one show the better time response performance of the proposed controller when compared to the PI controllers.

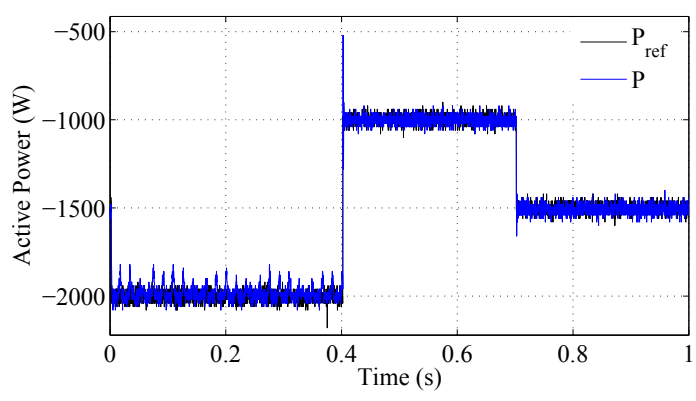

(a) Active power response

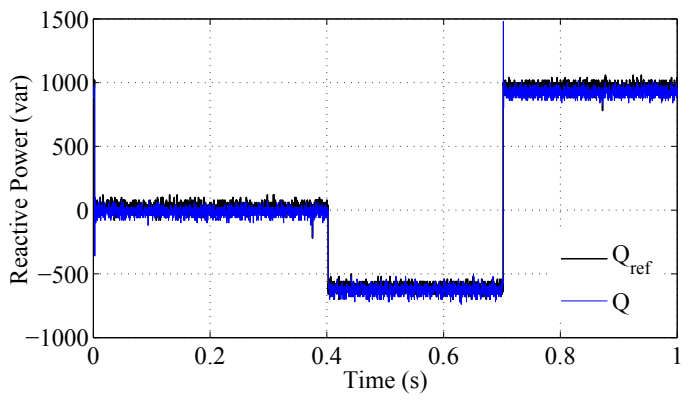

(b) Reactive power response.

Fig. 8. Test with constant speed.

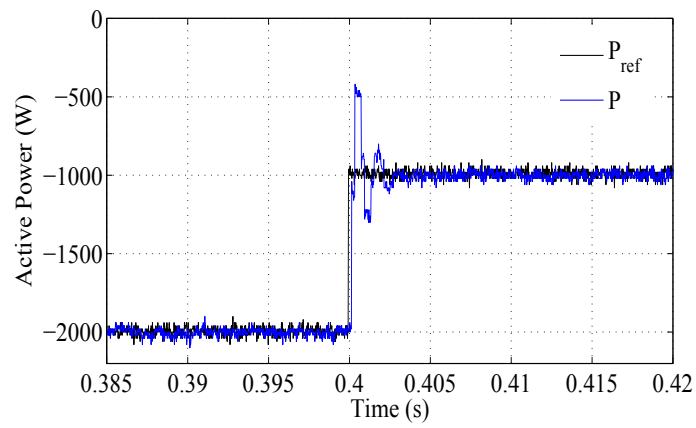

Fig. 9. Detailed active power response of proposed controller.

It can be noted that the proposed controller has an overshoot, but it is not relevant and does not damage the DFIG or the converter. Also, the settling time of the experimental results has a difference when compared with the theoretical value due to the digital controller implementation in the experimental setup.

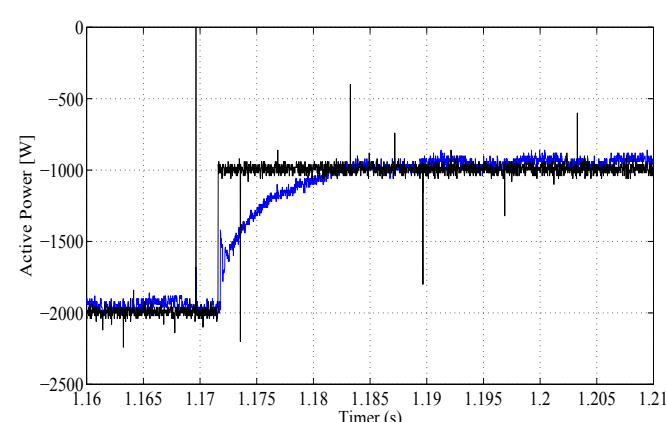

Fig. 10. Detailed active power response using PI controller

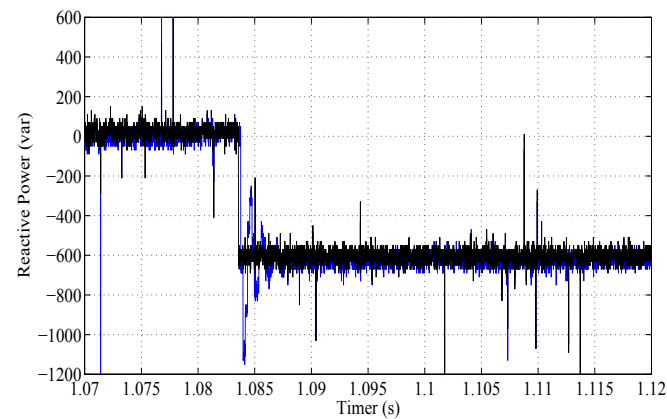

Fig. 11. Detailed reactive power response of proposed controller.

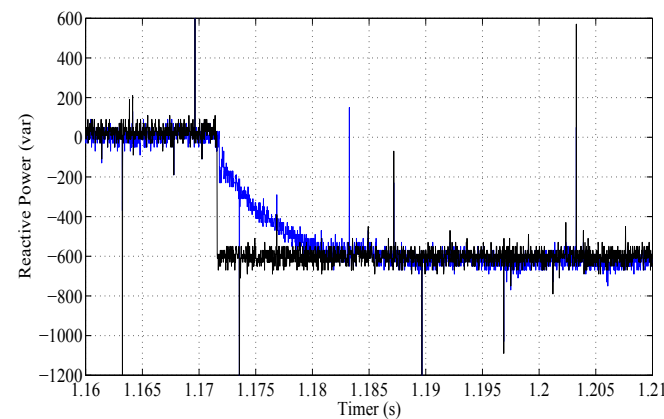

Fig. 12. Detailed reactive power response using PI controller.

The $d-q$ components of the rotor current for this test are shown in Figures 13 and 14. It can be verified that the measured results of the $d-q$ rotor current components quickly follow their respective references, showing a satisfactory performance. The rotor current in $\alpha \beta r$ and the phase $a$ stator current and voltage during this test are shown in Figures 15 and 16 , respectively.

Another test is made at several speed operations. During this test, the generator is driven with speed profile that varies from 2,050 rpm (supersynchronous) to $1,350 \mathrm{rpm}$ (subsynchronous), shown in Figure 17. In this operational test a constant active power of $2 \mathrm{~kW}$ with $\mathrm{PF}=1$ is used, as shown in Figure 18. It is verified that even in variable speed operation the controller is able to make a quick response of decoupled active and reactive powers without overshoot and with null steady state error, similarly to the previous test. The $d-q$ 
components of the rotor current and the rotor current in $\alpha \beta_{r}$ during this test are shown in Figures 19 and 20, respectively.

When an integral controller is used in the control system, a problem due to integral windup can occur. This is a common problem in analog controllers and it causes long periods of overshoot. The integral controllers of (27) and (28) are implemented in a DSP platform by using digital implementation and the time during oscillations is very short, as shown in results.

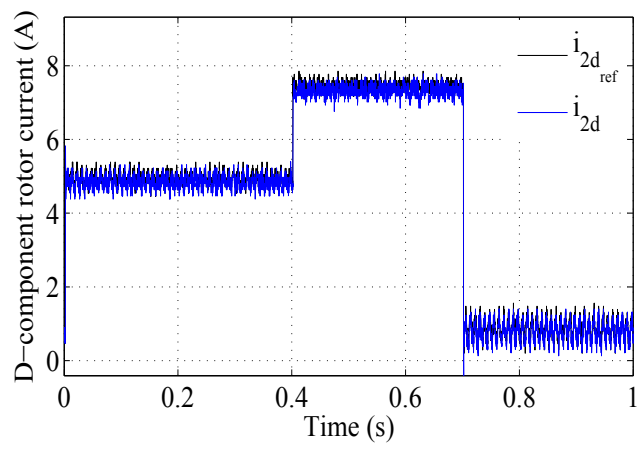

Fig. 13. Rotor current direct axis component.

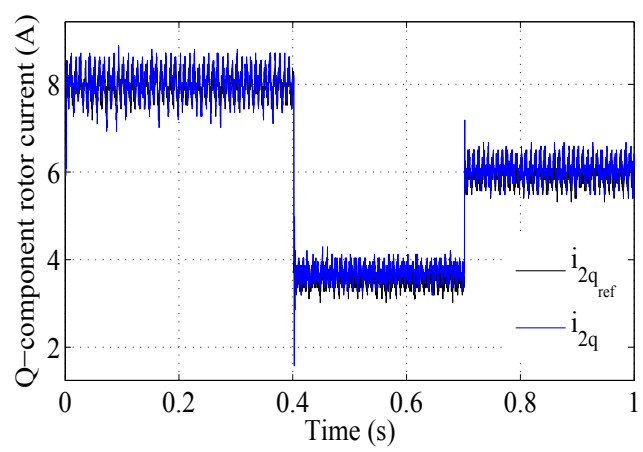

Fig. 14. Rotor current quadrature axis component.

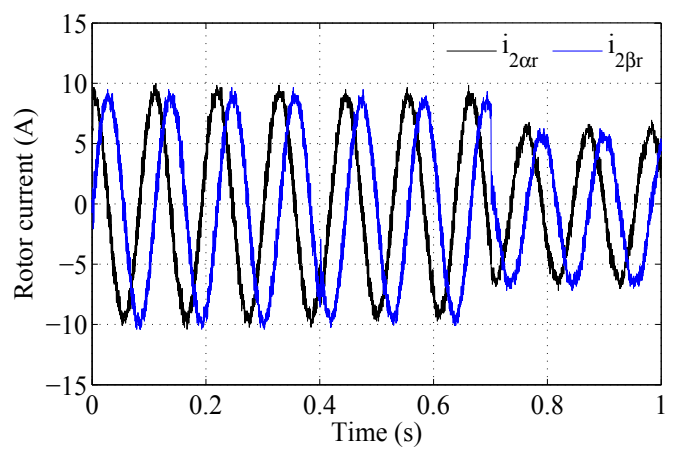

Fig. 15. Rotor current.

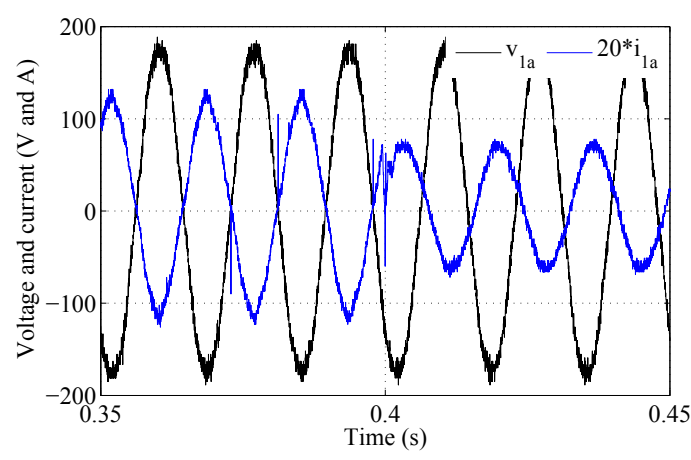

Fig. 16. Stator voltage and current.

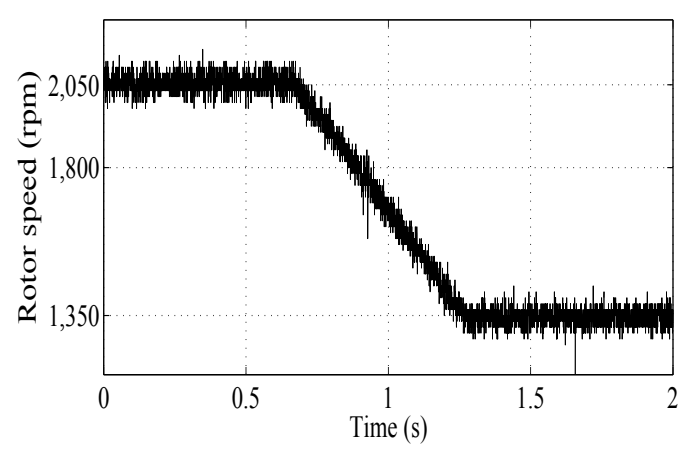

Fig. 17. Variable speed profile.

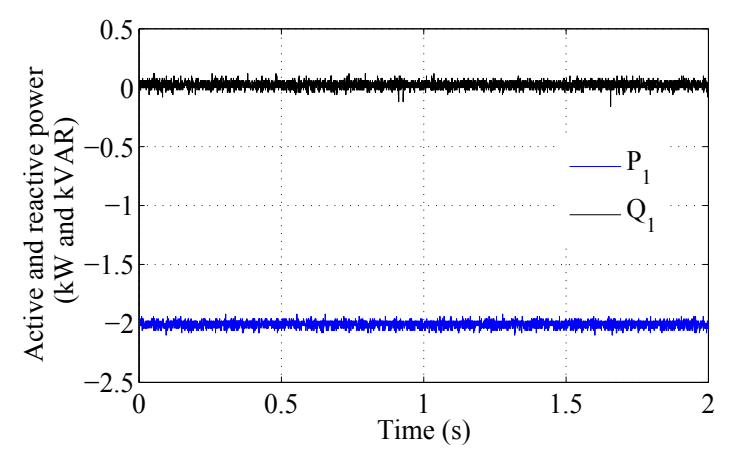

Fig. 18. Active and reactive power.

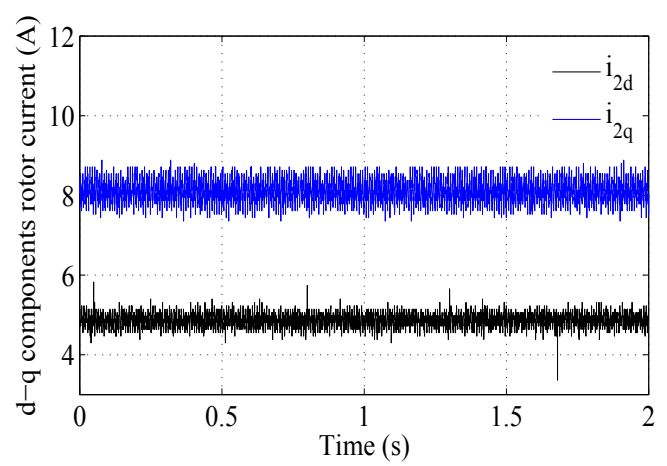

Fig. 19. Rotor current. 


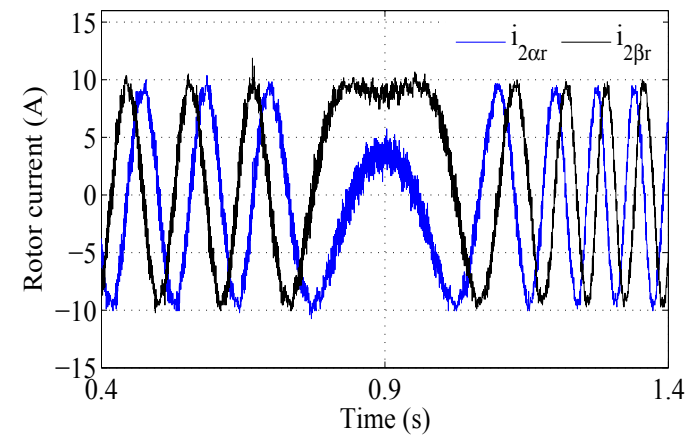

Fig. 20. Rotor current.

\section{CONCLUSION}

This paper presented a power control scheme for DFIG using stator flux orientation, state feedback control, and pole placement. The controller uses rotor voltage DFIG model where the rotor current is the state variable and the rotor voltage vector is the input. The controller allows to design the feedback and integral gains that calculate the required rotor voltages in order to the active and the reactive power values reach the desired reference values using rotor current vector loop. The experimental results of the proposed controller show better performance than obtained with PI controller. Also, it is confirmed the effectiveness of the controller during several operating conditions. In this way, this proposed controller can be used in wind energy applications with easy implementation and good performance.

\section{APPENDIX}

\section{A. DFIG Parameters}

$R_{s}=1.2 \Omega ; R_{r}=0.8 \Omega ; L_{m}=92 \mathrm{mH} ; L_{l s}=L_{l r}=6.18$ $\mathrm{mH} ; P P=2 ; P N=2.2 \mathrm{kVA}$; and $V_{N}=220 \mathrm{~V}$.

\section{B. Controller Parameters}

$\xi=0.13 ; t_{s}=3.5 \mathrm{~ms} ; \operatorname{pol}_{1,2}=-285.714 \pm j 2179.15 ;$ $k_{1}=-40 ; k_{2}=-50 ; k_{i 1}=12.6$ and $k_{i 2}=11.3$.

\section{ACKNOWLEDGEMENTS}

The authors thank to CNPq and FAPESP by partial the financial support.

\section{REFERENCES}

[1] G. Abad, J. López, M. A. Rodríguez, L. Marroyo, G. Iwanski, Doubly Fed Induction Machine: Modeling and Control for Wind Energy Generation Application. Wiley-IEEE Press, 2011.

[2] R. Datta, V. T. Rangathan, "Variable-speed wind power generation using doubly fed wound rotor induction machine - a comparison with alternative schemes," IEEE Transactions on Energy Conversion, vol. 17, no. 3, pp. 414-421, September 2002.

[3] B. H. Chowdhury, S. Chellapilla, "Double-fed induction generation control for variable speed wind power generation," Electric Power System Research, no. 76, pp. 786-800, June 2006.
[4] B. Hopfensperger, D. J. Atkinson, R. Lakin, "Stator-fluxoriented control of a doubly-fed induction machine with and without position encoder," IEE Proc.-Electr. Power Applications, vol. 147, no. 4, pp. 241-250, April 2000.

[5] J. Yao, H. Li, Z. Chen, X. Xia, X. Chen, Q. Li, Y. Liao, "Enhanced control of a dfig-based wind-power generation system with series grid-side converter under unbalanced grid voltage conditions," IEEE Transactions on Power Electronics, vol. 28, no. 7, pp. 3167-3181, June 2013.

[6] A. Tapia, G. Tapia, J. Ostolaza, J. Saenz, "Modeling and control of a wind turbine driven doubly fed induction generator," IEEE Transactions on Energy Conversion, vol. 18, no. 2, pp. 194-204, June 2003.

[7] F. P. anb T. Bouaouiche, M. Machmoum, "Advanced control of a doubly-fed induction generator for wind energy conversion," Electric Power Systems Research, vol. 79, no. 7, pp. 1085-1096, July 2009.

[8] M. Mohseni, S. Islam, M. Masoum, "Enhanced hysteresis-based current regulators in vector control of dfig wind turbines," IEEE Transactions on Power Electronics, vol. 26, no. 1, pp. 223-234, Jan 2011.

[9] D. Xiang, L. Ran, P. J. Tavner, S. Yang, "Control of a doubly fed induction generator in a wind turbine during grid falt ride-through," IEEE Transactions on Energy Conversion, vol. 21, no. 3, pp. 652-662, Setembro 2006.

[10] F. K. A. Lima, E. H. Watanabe, P. Rodriguez, Álvaro Luna, "Controle de gerador de inducao duplamente alimentado diante de afundamentos de tensao," Eletrônica de Potência, vol. 14, no. 3, pp. 189-199, Agosto 2009.

[11] J. Liang, D. F. Howard, J. A. Restrepo, R. G. Harley, "Feedforward transient compensation control for dfig wind turbines during both balanced and unbalanced grid disturbances," IEEE Transactions on Industry Applications, vol. 49, no. 3, pp. 1452-1462, May/June 2013.

[12] Z. Xin-fang, X. Da-ping, L. Yi-bing, "Predictive functional control of a doubly fed induction generator for variable speed wind turbines," in IEEE World Congress on Intelligent Control and Automation, vol. 4, pp. 33153319, June 2004.

[13] J. Morren, S. W. H. de Haan, "Ridethrough of wind turbines with doubly-fed induction generator during a voltage dip," IEEE Transactions on Energy Conversion, vol. 20, no. 2, pp. 435-441, June 2005.

[14] J. Guo, X. Cai, Y. Gong, "Decoupled control of active and reactive power for a grid-connected doubly-fed induction generator," in Third International Conference on Electric Utility Deregulation and Restructuring and Power Technologies. DRPT 2008., pp. 2620-2625, April 2008.

[15] S. Mishra, Y. Mishra, F. Li, Z. Dong, "Ts-fuzzy controlled dfig based wind energy conversion systems," IEEE Power Energy Society General Meeting, 2009. PES '09., pp. 1-7, July 2009.

[16] E. Kamal, M. Oueidat, A. Aitouche, R. Ghorbani, "Robust scheduler fuzzy controller of dfig wind energy 
systems," IEEE Transactions on Sustainable Energy, vol. 4, no. 3, pp. 706-715, July 2013.

[17] A. J. Sguarezi Filho, E. Ruppert, "A deadbeat active and reactive power control for doubly-fed induction generator," Electric Power Components and Systems, vol. 38, no. 5, pp. 592-602, March 2010.

[18] A. Sguarezi Filho, E. R. F. Filho, "Model-based predictive control applied to the doubly-fed induction generator direct power control," IEEE Transactions on Sustainable Energy, vol. 3, no. 3, pp. 398-406, July 2012.

[19] R. V. Jacomini, F. S. Trindade, A. J. S. Filho, E. R. Filho, "Decoupled power control for doublyfed induction generator using sliding-mode control," Przeglad Elektrotechniczny, vol. 8, no. 89, pp. 100-105, August 2013.

[20] A. Susperregui, M. Martinez, I. Zubia, G. Tapia, "Design and tuning of fixed-switching-frequency second-order sliding-mode controller for doubly fed induction generator power control," IET Electric Power Applications, vol. 6, no. 9, pp. 696-706, December 2012.

[21] W. Leonhard, Control of Electrical Drives. SpringerVerlag Berlin Heidelberg New York Tokyo, 1985.

[22] J. Holtz, J. Quan, J. Pontt, J. Rodríguez, P. Newman, H. Miranda, "Design of fast and robust current regulators for high-power drives based on complex state variables," IEEE Transactions Industrial Applications, vol. 40, no. 5, pp. 1388-1397, September/October 2004.

[23] A. J. S. Filho, E. R. Filho, "The complex controller for three-phase induction motor direct torque control," SBA Controle e automação., vol. 20, no. 2, pp. 256-262, 2009.

[24] K. Ogata, Engenharia de Controle Moderno. LTC, 2000.

[25] R. C. Dorf, R. H. Bishop, Modern Control Systems Analysis \& Design. Addison Wesley, 1998.

[26] A. M. Khambadkone, R. Datta, V. T. Ranganathan, "Modeling and rotor current control of doubly-fed induction machine with complex signal flow graphs," in IEEE International Conference on Power Electronic Drives and Energy Systems for Industrial Growth PEDES '98, pp. 1-3, December 1998.

[27] F. Blaabjerg, R. Teodorescu, M. Liserre, A. V. Timbus, "Overview of control and grid synchronization for distributed power generation systems," IEEE Transactions on Industrial Electronics, vol. 53, no. 5, pp. 1398-1409, Oct. 2006.

[28] Y. Xue, X. Xu, T. G. Halbetler, D. M. Divan, "A low cost stator flux oriented voltage source variable speed drive," in IEEE Industrial Aplications Society Annual Meetting, Conference Record of the 1990, vol. 1, pp. 410-415, Oct 1990.

[29] J. Hu, W. Zhang, H. Wang, Y. He, "Improved mras observer and sensorless control of dfig during network voltage unbalance," in IEEE International Electric Machines and Drives Conference, 2009. IEMDC '09., pp. 1486-1491, May 2009.

\section{BIOGRAPHIES}

Alfeu Joãozinho Sguarezi Filho received his bachelor degree in Electrical Engineering from Faculdade Área 1, his Master degree and his Ph.D. degree from University of Campinas in Brazil, respectively in 2005, 2007 and 2010. He was working as researcher at Campinas University by FAPESP pos-doctoral program from 2010 to 2011. Now, he is a professor at Federal University of ABC - UFABC, in Santo André, Brazil, teaching in the areas of Electrical Machines, Power Electronics and Electrical Drives. His research interests are machine drives, doubly-fed induction generators, power control, and electrical power systems.

André Luiz de Lacerda Ferreira Murari, received the B.S. degree in electrical engineering in 2013 from University of Campinas, Brazil. He is currently a Master of Science Student at University of ABC (UFABC), Santo André, and his research interests are: electrical machines, machine control, power electronics, wind energy and electric power systems.

Carlos Eduardo Capovilla was born in Vinhedo, Brazil, on March 6, 1977. He received the B.S. degree from the University of São Paulo, Brazil, in 2001 and the M.Sc. and Ph.D. degrees from the University of Campinas, Brazil, in 2004 and 2008, respectively, all in electrical engineering (microelectronics). He is currently a Professor with the Federal University of ABC (UFABC), Santo André, Brazil. His current research interests are integrated circuits and electronic for wireless control and smart grid applications.

José Alberto Torrico Altuna, received the B.S. degree in electrical engineering in 1986 from National University of Engineering in Lima, Peru, MS degree in Electrical Engineering in 1997 and Ph.D. degree in Electrical Engineering in 2002 both from the University of Campinas, Brazil. He was Associated Professor at the National Engineering University in Lima, Peru. He was engaged with R\&D projects at Whirlpool S. A. and Commodity Systems company. His research interests are: electrical machines, machine control, power electronics, wind energy and electric power systems. He is currently post-doctorate Fellow of CAPES PNPD program at UFABC Brazil.

Rogério Vani Jacomini was born in Santa Barbara D’ Oeste, Sao Paulo, Brazil, in 1979. Received the B.S. degree in electrical engineering from Salesian University Center of Sao Paulo, Brazil, in 2004, the M.S. and Ph.D. degree from University of Campinas, Brazil, respectively in 2008 and 2012. He was researcher at University of ABC - UFABC, Brazil. Currently, he is a professor at IFSP. His research interests include $\mathrm{AC}$ drives and doubly fed induction machine. 